\title{
IMPACT OF TIMING OF SURGERY \& ROUTINE BILIARY SAMPLING IN ACUTE CALCULOUS CHOLECYSTITIS
}

\author{
Tharun Ganapathy Chitrambalam¹, Udhayam S2, Shruthi Chandrasekar', Manimaran4 \\ ${ }^{1}$ Assistant Professor, Department of General Surgery, SRM Medical College and Research Institute, SRM University. \\ 2Postgraduate, Department of General Surgery, SRM Medical College and Research Institute, SRM University. \\ ${ }^{3}$ Postgraduate, Department of General Surgery, SRM Medical College and Research Institute, SRM University. \\ ${ }^{4}$ Postgraduate, Department of General Surgery, SRM Medical College and Research Institute, SRM University.
}

\section{ABSTRACT}

\section{BACKGROUND}

Aims and objectives - A rise has been noted in the incidence of gallstone disease and their associated complications. This clinical study was conducted with the aim of analysing the various aspects of gall stone diseases focusing on the timing of surgery, and intraoperative biliary sampling correlated to the complication rates in acute calculous cholecystitis.

\section{MATERIALS AND METHODS}

50 cases of acute calculous cholecystitis were evaluated with respect to incidence, clinical presentation, comorbidities, tim ing of surgery, operative difficulty, post-operative complications, hospital stay, bile culture, histopathology and stone analysis.

\section{RESULTS}

The overall incidence of gall stones in patients was $0.7 \%$ of all hospital admissions. The mean age group was 43.92 years with a female to male ratio of 2.13:1. Right hypochondrial and epigastric pain were the most common presenting complaints. Preoperative evaluation with ultrasonogram showed a good correlation with the per-operative findings in $80 \%$ of cases. All cases underwent laparoscopic cholecystectomy. Operative difficulty was least when surgery was done within three weeks from the time of presentation. $24 \%$ cases had intra-operative complications. Escherichia coli was the most common organism grown in bile culture and there was a statistical significance between positive bile culture and post-operative complications. Pure cholesterol stones were less common on histopathological examination.

\section{CONCLUSION}

Early surgical intervention in cholecystitis reduces complications, length of hospital stay and relapse of symptoms during waiting period for surgery. The study suggests routine sampling of bile for bacterial culture and stone analysis in all cholecystectomy cases.

\section{KEYWORDS}

Lap. Cholecystectomy, Acute Cholecystitis, Bile Culture, Timing of Cholecystectomy, E. coli.

HOW TO CITE THIS ARTICLE: Chitrambalam TG, Udhayam S, Chandrasekar S. Impact of timing of surgery \& routine biliary sampling in acute calculous cholecystitis. J. Evolution Med. Dent. Sci. 2016;5(96):7068-7070, DOI: 10. 14260/jemds/2016/1599

\section{BACKGROUND}

Gall stones are one of the most common problems affecting the gastrointestinal tract and biliary system.[1] There has been a marked rise in the incidence of gallstones in the western countries. ${ }^{[2]}$ The introduction of western diet has increased the prevalence of gall stones in Asian countries.[3] Most patients remain asymptomatic throughout their life and may only be detected incidentally on ultrasound and CT scan. Nearly 3\% of these individuals become symptomatic (Biliary colic) per year, of which $3 \%$ to $5 \%$ of them develop complications per year.[1]

Financial or Other, Competing Interest: None.

Submission 25-10-2016, Peer Review 20-11-2016,

Acceptance 26-11-2016, Published 01-12-2016.

Corresponding Author:

Dr. Tharun Ganapathy Chitrambalam,

Vanaja Hospital,

M.A. Koil Street,

M.A Nagar,

Padiyanallur

Chennai- 600052

E-mail: drtarunchitrambalam@gmail.com

DOI: $10.14260 /$ jemds/2016/1599
Although, laparoscopic cholecystectomy has become the standard of care in treatment of gall stone disease, the timing of cholecystectomy, its relevance to complications and use of prophylactic antibiotics has always been a subject of debate.

Owing to the constant rise in the occurrence of gall stones and its variable presentations, this clinical study was conducted with the aim of analysing the various aspects of gall stone diseases focusing on the timing of surgery and intraoperative biliary sampling correlated to the complication rates.

\section{MATERIALS AND METHODS}

Fifty patients with acute calculous cholecystitis admitted in the surgical units of SRM Medical College Hospital and Research Centre from March 2015 - September 2016 were constituted for the study. After thorough clinical examination and relevant imaging, the acute phase was treated with parenteral antibiotics and subjected to laparoscopic cholecystectomy. Per-operatively, after creating pneumoperitoneum, general laparoscopy was done and bile was obtained from the gall bladder with a suction needle and sent for culture and sensitivity. The operative findings and postoperative complications were recorded and carefully analysed. 
The gallstones were sent for biochemical analysis, bile sent for culture and the gall bladder for histopathological examination. Antibiotics were administered only on positive bile cultures. Patients unfit for surgery, refusing to give consent, patients with major bleeding disorders, pregnancy, cirrhosis with portal hypertension were all excluded from the study. All data were recorded, statistically analysed and compared with previous standard studies.

\section{RESULTS}

The overall incidence of gallstone diseases was $0.7 \%$ of all hospital admissions $(44,137)$ from March 2015 to September 2016. The 50 patients of gallstone diseases studied ranged between 18 and 75 years of age. The mean age being 43.6 yrs. The maximum number of cases occurred in the third and fourth decades. Of the 50 cases, 34 (68\%) were females, making the female: male ratio 2.13:1. Right hypochondrial pain with nausea, vomiting were the presenting complaint in majority of cases about 24(48\%). Murphy's sign was positive in 18 cases. Fever was present in five cases. 7 of our cases were diabetic and 2 of them hypersensitive and 4 of them had both diabetes and hypertension. One patient had bronchial asthma. Laboratory investigations were done as a part of routine workup. Serum bilirubin was found to be elevated in four cases, with a maximum of $6.2 \mathrm{mg} / \mathrm{dL}$. 7 cases had elevated cholesterol levels and one of the patients was a chronic kidney disease case, who had elevated rental parameters. Plain x-ray abdomen was taken in all cases. However, radio-opaque shadows suggestive of a stone could not be identified in any of them. Ultrasound of abdomen was adequate to make a diagnosis of acute calculous cholecystitis except in the four cases with elevated bilirubin levels, which were further evaluated with CT abdomen and one of the cases, underwent MRCP. USG showed good correlation with per operative findings in $40(80 \%)$ cases.

Most of the cases $34(68 \%)$ were assessed as ASA score I, $15(30 \%)$ as ASA score II, 1 (2\%) as ASA score III. Many cases of acute cholecystitis were managed conservatively in the initial periods and taken up for surgery after intervals of one to eight weeks. Majority of the cases were taken up for surgery after an interval of more than 3 weeks as shown in fig.1. In the interval between initial presentation and the time of elective surgery, many patients became symptomatic and a few required re-admissions. A sizeable number of patients who were operated after an interval of more than 3 months experienced progressive/recurrent symptoms. Two of these cases were readmitted and underwent surgery at the earliest. The ' $p$ ' value was less than 0.05 denoting a statistical significance in number of patients who experience recurrent symptoms during the longer interval of elective cholecystectomy. All the 50 cases were operated for laparoscopic cholecystectomy. Patients who underwent surgeries after an interval of 3 weeks and later encountered less operative difficulty as in table 1 , least when done after three weeks (4.17\%). 6 patients faced complications, 1 bile duct injury, 4 subtotal cholecystectomies due to frozen Calot's triangle, 1 case of mild post-operative jaundice which settled in few weeks. The average hospital stay and laparoscopic cholecystectomy was 2-3 days, except in few cases where the stay was extended to 3 or more days. Post-operative stay was slightly prolonged in cases which encountered operative difficulty.
Intraoperative biliary sampling was done for all cases which revealed E. coli growth in 16 (32\%), 2 (4\%) Klebsiella, $2(4 \%)$ Enterococcus and $30(60 \%)$ cases had no growth on cultures as shown in table 2. $34(68 \%)$ cases had acute cholecystitis and 16 (32\%) had chronic cholecystitis on histopathological report as in table 3 . On biochemical analysis as in table 4, mixed stones were the commonest constituting $40 \%$ of all stones.

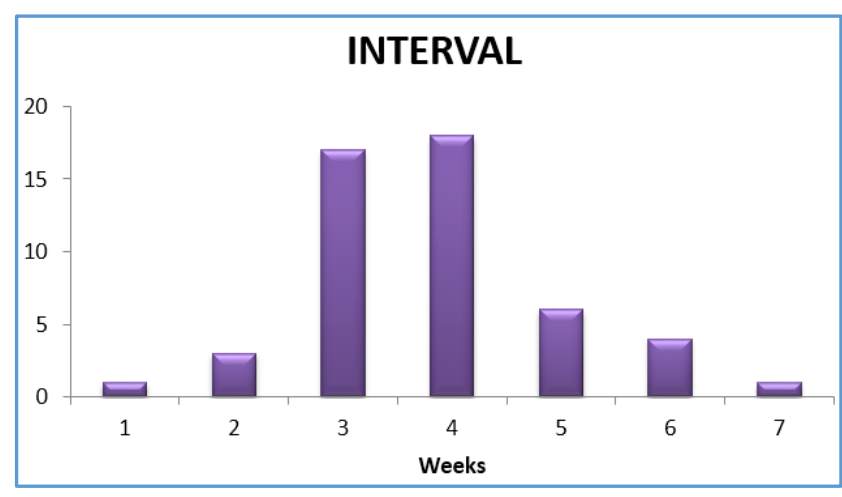

Figure 1. Variable Time Interval between Initial Presentation and Timing of Laparoscopic Cholecystectomy

\begin{tabular}{|c|c|c|c|c|}
\hline & Frequency & Percent & $\begin{array}{c}\text { Valid } \\
\text { Percent }\end{array}$ & $\begin{array}{c}\text { Cumulative } \\
\text { Percent }\end{array}$ \\
\hline $\begin{array}{c}\text { Difficult } \\
\text { Calot's } \\
\text { triangle }\end{array}$ & 12 & 24.0 & 24.0 & 24.0 \\
\hline None & 38 & 76.0 & 76.0 & 100.0 \\
\hline Total & $\mathbf{5 0}$ & $\mathbf{1 0 0 . 0}$ & $\mathbf{1 0 0 . 0}$ & \\
\hline \multicolumn{5}{|c|}{ Table 1. Operating Difficulty } \\
Encountered in the Study Series
\end{tabular}

\begin{tabular}{|c|c|c|c|c|}
\hline & Frequency & Percent & $\begin{array}{c}\text { Valid } \\
\text { Percent }\end{array}$ & $\begin{array}{c}\text { Cumulative } \\
\text { Percent }\end{array}$ \\
\hline E. coli & 16 & 32.00 & 60.0 & 60.0 \\
\hline No growth & 30 & 60.00 & 32.0 & 92.0 \\
\hline Enterococcus & 2 & 4.0 & 4.0 & 96.0 \\
\hline Klebsiella & 2 & 4.0 & 4.0 & 100.0 \\
\hline Total & $\mathbf{5 0}$ & $\mathbf{1 0 0 . 0}$ & $\mathbf{1 0 0 . 0}$ & \\
\hline \multicolumn{6}{|c|}{ Table 2. Organisms Grown on Biliary Culture } \\
\hline
\end{tabular}

\begin{tabular}{|c|c|c|c|c|c|}
\hline \multicolumn{2}{|c|}{} & Frequency & Percent & $\begin{array}{c}\text { Valid } \\
\text { Percent }\end{array}$ & $\begin{array}{c}\text { Cumulative } \\
\text { Percent }\end{array}$ \\
\hline \multirow{3}{*}{ Valid } & AC & 34 & 68.0 & 68.0 & 68.0 \\
\cline { 2 - 6 } & CC & 16 & 32.0 & 32.0 & 100.0 \\
\cline { 2 - 5 } & Total & $\mathbf{5 0}$ & $\mathbf{1 0 0 . 0}$ & $\mathbf{1 0 0 . 0}$ & \\
\hline \multicolumn{6}{|c|}{ Table 3. Histopathology Report } \\
\hline
\end{tabular}

\begin{tabular}{|c|c|c|c|c|c|}
\hline \multicolumn{2}{|c|}{} & Frequency & $\%$ & $\begin{array}{c}\text { Valid } \\
\text { Percent }\end{array}$ & $\begin{array}{c}\text { Cumulative } \\
\text { Percent }\end{array}$ \\
\hline \multirow{4}{*}{ Valid } & Mixed & 20 & 40.0 & 40.0 & 40.0 \\
\cline { 2 - 6 } & Oxalate & 12 & 24.0 & 24.0 & 24.0 \\
\cline { 2 - 6 } & Phosphate & 10 & 20.0 & 20.0 & 20.0 \\
\cline { 2 - 6 } & Cholesterol & 5 & 10.0 & 10.0 & 10.0 \\
\cline { 2 - 6 } & Pigment & 3 & 6.0 & 6.0 & 6.0 \\
\cline { 2 - 6 } & Total & $\mathbf{5 0}$ & $\mathbf{1 0 0 . 0}$ & $\mathbf{1 0 0 . 0}$ & \\
\hline \multicolumn{6}{|c|}{ Table 4. Biochemical Analysis of Stones } \\
\hline
\end{tabular}




\section{DISCUSSION}

In a series of early laparoscopic cholecystectomy by T. Siddiqui et al,(2008) and Skorus et al, in a review of 92 papers concluded shorter total hospital stay with no significant differences in conversion rates or complications. ${ }^{[4,5]}$ In a recent large Swedish series by Blohm et al, concluded early laparoscopic cholecystectomy for acute cholecystitis offers an advantage in the length of hospital stay without increasing the morbidity or mortality with caption 'the sooner, the better'.[6] Similarly in our study, complication rates and operating difficulties were lesser in patients who were operated in the initial period and patients on long waiting period suffered relapse of symptoms and required readmissions. Our study also concludes that early intervention reduces complications and length of hospital stay.

Our study shows a statistical significance between the positive bile culture and post-operative complications. Similarly, D. Fuks et al, (2013) suggests biliary sampling in severe cases and reports that continuation of antibiotic treatment after early cholecystectomy is unnecessary in acute calculous cholecystitis.[7] Intraoperative biliary sampling was done for all cases in our study which revealed E. coli to be the commonest organism grown on culture in correlation to a randomised series of 240 patients by Petakovic et al in 2002 concluding $\mathrm{E}$. coli as positive culture in $55 \%$ of cases.

\section{CONCLUSION}

Early surgical intervention in cholecystitis reduces complications, length of hospital stay and relapse of symptoms during waiting period for surgery. The study suggests routine sampling of bile for bacterial culture and stone analysis in all cholecystectomy cases.

\section{REFERENCES}

1. Oddsdottir M, Pham T, Hunter JG. Gallbladder and extrahepatic biliary system. In: Brocade CF. (edr) Schwartz's principles of surgery. 9th edn. USA: McGraw Hill companies Inc 2009:1135-66.

2. Alfred S, Robert JC. Steele, Abdul Rahimmoosa- disorders of biliary tract. In: Cuscheri A. (edr) Essential surgical practice, higher surgical training in general surgery. $4^{\text {th }}$ edn. Arnold Hodder headline group 2002:375-452.

3. Venneman NG, Erpecum KJV. Pathogenesis of gallstones. Gastroenterology Clinics of North America 2010;39(2):171-83.

4. Siddiqui T, MacDonald A, Chong PS, et al. Early versus delayed laparoscopic cholecystectomy for acute cholecystitis: a meta-analysis of randomized clinical trails. The American Journal of Surgery 2008;195(1):407.

5. Skouras C, Jerald O, Deshpande R, et al. Is early laparoscopic cholecystectomy for acute cholecystitis preferable to delayed surgery?: best evidence topic (BET). International Journal of Surgery 2012;10(5):250-8.

6. Blohm M, Osterberg J, Sandblom G, et al. The Sooner, the better? the importance of optimal timing of cholecystectomy in acute cholecystitis: data from the national Swedish registry for gallstone surgery, GallRiks. J Gastrointest Surg 2016:1-8.

7. Fuks D, Cosse C, Regimbeau JM. Antibiotic therapy in acute calculous cholecystitis. Journal of Visceral Surgery 2013;150:3-8. 